Revistade
Economìd
Contemporâned

\title{
MODELOS HETERODOXOS DE CRESCIMENTO EM ECONOMIAS ABERTAS: UMA EXTENSÃO DOS MODELOS DE KALDOR-THIRLWALL
}

\author{
André Luís Cabral de Lourenço ${ }^{a}$ \\ ${ }^{\mathrm{a}}$ Departamento de Economia da Universidade Federal do Rio Grande do Norte (UFRN).
}

Artigo recebido em 17/04/2014 e aceito em 13/11/2015.

RESUMO: O artigo teve por objetivo central contribuir para o processo de construção de modelos de crescimento heterodoxos para economias abertas na linha de Kaldor (1970) e Thirlwall (1979). Para tanto: i) recuperou os elementos comuns a esses modelos que forneceram uma base teórica geral para a construção de modelos; ii) buscou melhorar a articulação entre as taxas de crescimento da demanda agregada e a taxa de crescimento permitida pela restrição externa, bem como preencher o vácuo decorrente da ausência do crescimento da demanda agregada; iii) resenhou a literatura que visa melhorar a modelagem da restrição externa nessa linha teórica, recolhendo importantes inspirações para construir uma forma de modelar a restrição externa que evitasse algumas das deficiências presentes na literatura; iv) explorou algumas das propriedades e aspectos mais salientes da solução assim gerada.

PALAVRAS-CHAVE: modelos de crescimento heterodoxos; restrição externa; demanda agregada.

CLASSIFICAÇÃO JEL: O40; F43; F34. 


\section{HETERODOX MODELS OF GROWTH IN OPEN ECONOMIES: AN EXTENSION OF KALDOR- THIRLWALL MODELS}

ABSTRACT: The article aims as a central tenet to contribute to the process of building heterodox growth models for open economies in line with Kaldor (1970) and Thirlwall (1979). Therefore it: i) retrieved the elements common to these models that provided a general theoretical basis for the model building process, ii) sought to improve coordination between the growth rates of aggregate demand and that allowed by the external constraint, as long as filled the resulting gaps in terms of modeling the growth of aggregate demand, iii) reviewed the literature intended to improve the modeling of the external constraint in this theoretical line, gathering important insights to build a model of external constraints that tried to prevent some of the deficiencies which remained at that literature; iv) explored some of the properties and the most salient features of the solution built in that manner.

KEYWORDS: heterodox growth models; external constraint; aggregated demand. 


\section{INTRODUÇÃO}

Em artigo anterior (Lourenço et al., 2012), arguimos que os modelos heterodoxos de crescimento para economias abertas na linha de Kaldor (1970) e de Thirlwall (1979) são adequados também (com alguns ajustes de interpretação) para o tratamento do crescimento dos espaços regionais intranacionais. Aprofundando-se nessa temática, o presente artigo pretende desdobrar observações resultantes das comparações entre esses dois modelos canônicos, bem como questionar certos aspectos de ambos. Algumas extensões, particularmente no que concerne à formalização da restrição externa, serão também abordadas. Assim procedendo-se, espera-se caminhar no sentido de estabelecer elementos que façam parte de um referencial teórico mais firme, capaz de promover maior "fertilização cruzada" entre as áreas de teoria do crescimento e de economia regional. Embora em termos de proposta haja similitudes entre o presente artigo e o de Blecker (2009), há significativa divergência de opiniões. Ademais, o direcionamento à discussão de economia regional, ausente naquele autor, conduz o texto para caminhos diversos.

As principais hipóteses desenvolvidas por este artigo (e a estrutura destinada a tal desenvolvimento) propõem que:

i) os elementos comuns aos modelos canônicos de Kaldor e de Thirlwall fornecem uma base teórica importante para a construção de modelos de análise do crescimento regional dedica-se a esse aspecto o item 2 ;

ii) contudo, a forma de articulação entre as taxas de crescimento da demanda agregada e da taxa de crescimento máximo permitida pela restrição externa está mal concatenada nesses modelos (principalmente em Kaldor), fazendo-se necessário um esforço no sentido de melhor associá-las; ademais, a falta de concatenação gerou um vácuo na modelagem adequada do crescimento da demanda agregada nesses modelos (dedica-se às tarefas daí decorrentes o item 3;

iii) a modelagem dos aspectos referentes à restrição do balanço de pagamentos nos modelos originais de Kaldor e de Thirlwall apresenta dificuldades importantes, que deram origem a toda uma literatura em torno de um bom número de versões secundárias que procuram sanar tais deficiências (o item 4 dedica-se a resenhar algumas dessas versões, no intuito de obter importantes inspirações para o trabalho de construção do item seguinte);

iv) é possível, com base nessa inspiração, agregar elementos que permitam construir uma modelagem da restrição externa que evite algumas das deficiências presentes nos modelos resenhados no item anterior (dedica-se o item 5 a dar concretude a tal construção, bem como a explorar algumas de suas propriedades e aspectos mais salientes). A maior preocupação consistirá em tentar mo- 
delar a restrição externa de longo prazo de forma a manter a possibilidade de geração de deficits/superavits permanentes em conta corrente, sem que eles acarretem o crescimento explosivo do passivo externo líquido.

\section{CONFLUÊNCIAS ENTRE KALDOR E THIRLWALL:}

\section{A COLUNA VERTEBRAL PARA UMA VISÃO INTEGRADA DO CRESCIMENTO REGIONAL}

Observando os dois modelos anteriormente descritos sob um ângulo mais geral, notam-se algumas semelhanças importantes, responsáveis pela caracterização de ambos como de natureza claramente heterodoxa. Destaca-se nesse particular a adesão comum ao princípio da demanda efetiva como elemento teórico central ${ }^{1}$, válido não apenas em contextos de curto prazo em que predomina a rigidez de preços e salários, mas sim em qualquer prazo cronológico, mesmo que longo, e independentemente do grau de flexibilidade presente no sistema de preços.

Este aspecto, que permite caracterizar tais modelos como de crescimento "liderado pela demanda”, tem como contrapartida teórica necessária a visão de que as restrições físicas tradicionais de oferta - disponibilidade de capital e de mão de obra perfazem papel absolutamente secundário destes. A rigor, pode-se imaginar que tais restrições possam manifestar-se apenas em períodos de tempo relativamente curtos, mas que em prazos mais longos certos mecanismos entrariam em operação de modo a relaxar tais restrições.

No que concerne à disponibilidade de capital, a hipótese comum a ambos os modelos é de que o investimento seguiria uma trajetória guiada pela teoria do acelerador / supermultiplicador. Esta acarretaria a conclusão de que a taxa de crescimento do estoque de capital é determinada pela taxa de crescimento dos componentes autônomos da demanda (consumo autônomo, gastos governamentais e exportações), tendendo continuamente para a mesma e a ela se igualando em configurações de equilíbrio de longo prazo. Essa maleabilidade do estoque de capital à demanda afastaria a possibilidade de que a acumulação de capital representasse um óbice ao crescimento, ao menos do ponto de vista do longo prazo ao qual os modelos em questão estão referidos.

Já no que diz respeito à disponibilidade de mão de obra, nenhum dos modelos é explícito em relação ao mecanismo de ajuste adotado para eliminar sua possível escassez frente ao crescimento. Em Kaldor, a taxa de crescimento salarial é tratada como exógena; sua consequente independência em relação ao nível de atividade e/ou à taxa

\footnotetext{
1 Abstrai-se nesse aspecto a curiosa contribuição de Kaldor para o caso dos países agrícolas.
} 
de desemprego sugere a presença de um reservatório de mão de obra de longa duração, como o setor de subsistência no modelo de Lewis (1954), ou quiçá de um exército industrial de reserva com capacidade de autorrecomposição (como em Marx, 1867)2. Thirlwall, por sua vez, não vê necessidade de considerar explicitamente o crescimento salarial no texto de 1979, enquanto, em outros textos (p. ex., Thirlwall, 2005), ele adota postura idêntica à de Kaldor. A justificativa explícita oferecida por este autor é também a de Lewis, todavia estendida aos países desenvolvidos, sob a justificativa de que os trabalhos empíricos de Kindleberger (1967) e de Cornwall (1977) haviam demonstrado que mesmo nesses países o cenário de excesso estrutural de mão de obra também se manifestava (McCombie e Thirlwall, 1994, p. 156). Em Thirlwall (2005, p. 75) esse fator é justificado mediante defesa da ideia de que a taxa de crescimento natural também é endógena devido ao fato de serem extremamente elásticos ao crescimento da demanda por trabalho: a) a taxa de participação; b) o número de horas trabalhadas por trabalhador; c) a taxa de imigração. Ademais, o crescimento econômico mais acelerado tenderia a acelerar o crescimento da produtividade do trabalho, via lei de Verdoorn.

Blecker (2009, p. 18) considerou exagerada a total insensibilidade da taxa de crescimento salarial ao crescimento da demanda por trabalho presente no modelo de Kaldor. Desenvolvimentos nesse sentido, que implicam estender os modelos para contemplar detalhadamente a conexão entre as teorias do crescimento e as de inflação, porém, podem ser encontrados em Lavoie (1992, p. 405-414) e em Porcile e Lima (2009). Nenhuma das conclusões fundamentais de Kaldor e de Thirlwall, cabe ressaltar, resultam alteradas. Há, pelo contrário, uma melhor elaboração dos mecanismos inflacionários que emergem quando a economia supera a taxa máxima de crescimento compatível com a restrição do balanço de pagamentos. Mas, considerando que os resultados fundamentais não são alterados, optamos, em prol da maior simplicidade e da manutenção do foco nos aspectos considerados prioritários, manter, na modelagem que se segue nos itens seguintes, a taxa de crescimento salarial como estritamente exógena.

Além de eliminar a possibilidade de óbices ao crescimento de longo prazo pela insuficiência de capital, a adoção do acelerador / supermultiplicador gera como resultado também o fato de que a taxa de expansão da demanda agregada - que lidera o crescimento em ambos os modelos - depende exclusivamente da taxa de expansão dos componentes autônomos da mesma demanda. Sem negar relevância ao efeito acelera-

\footnotetext{
2 Esta afirmação diz respeito às formalizações do modelo de Kaldor. Em Kaldor (1966), adere-se explicitamente às ideias citadas, mas ainda não formalmente.
} 
dor como elemento explicativo do comportamento do investimento, outras vertentes da teoria heterodoxa arrolam, contudo, uma série de outras variáveis explicativas - expectativas (Keynes, 1936, cap. 11 e 12), progresso técnico (Kalecki, 1954, cap. 8 e 9; Dosi et al., 2004), margem de lucro (Eichner, 1973; Bhaduri e Marglin, 1990), taxa de juros e preços de ativos financeiros (Keynes, 1936, caps. 11, 12 e 17; Minsky, 1986, cap. 8 e 9; Kalecki, 1954, cap. 8 e 9; Dosi et al., 2004), disponibilidade de crédito (Davidson, 1994, p. 57-58; Minsky, 1986, cap. 8 e 9) etc. - como capazes de afetar o investimento significativamente, tornando-o assim parcialmente autônomo em relação às condições de demanda. Seguidores do enfoque do investimento completamente induzido contra-argumentam afirmando que, ainda que do ponto de vista microeconômico todas essas demais variáveis possam ser importantes, sob o ângulo macroeconômico a admissão de qualquer uma delas na função investimento exigiria que as empresas aceitassem operar com graus de utilização da capacidade diferentes dos desejados no longo prazo marshalliano, o que contradiria a hipótese de racionalidade (Garegnani, 1976; Amadeo e Dutt, 1990; Serrano, 1995). Os demais enfoques não se sentem presos ao conceito de racionalidade substantiva e/ou ao de equilíbrio de longo prazo nas formas presentes naquela abordagem (Shacke, 1968; Carvalho, 1985).

\section{DEMANDA AGREGADA, RESTRIÇÃO EXTERNA E CRESCIMENTO NO ESPAÇO}

No campo do ajuste do balanço de pagamentos, os dois modelos rejeitam os mecanismos de ajuste convencionais de longo prazo exclusivamente centrados em efeitossubstituição. Adotam, pelo contrário, a ideia heterodoxa de que o ajuste do balanço de pagamentos - tanto no nível nacional quanto no subnacional - ocorre substancialmente por meio do efeito-renda, mesmo em prazos longos. Segue-se inevitavelmente a possibilidade de que uma restrição de balanço de pagamentos se torne operacional, perturbando o crescimento econômico dos países e regiões a ela sujeitos.

$\mathrm{Na}$ modelagem da relação entre o crescimento da demanda e a restrição externa, contudo, surge uma diferença entre as duas abordagens. Enquanto Thirlwall admite a possibilidade de que essa restrição nem sempre esteja operacional, Kaldor tenta construir uma teoria na qual a taxa de crescimento da demanda seja, ao mesmo tempo, a taxa de crescimento máxima permitida pela restrição externa no longo prazo. Assim, a economia estaria sistematicamente operando sob restrição externa. Contudo, a despeito dessa intenção, o fato é que Kaldor não é bem-sucedido em sua modelagem sobre este ponto. Como observado em artigo anterior (Lourenço et al., 2012), na equação que conecta o crescimento econômico à restrição de balanço de pagamentos 
postula-se que: a) o orçamento governamental esteja equilibrado; e, simultaneamente, que b) a poupança e o investimento do setor privado se igualem. Contudo, como explica Freitas (2003, p. 9-12): 1) não há nenhum mecanismo endógeno proposto que seja capaz de garantir que o orçamento do governo se equilibre no longo prazo; 2) o ajuste endógeno da poupança privada ao investimento privado se dá por meio de variações da margem de lucro e da distribuição de renda, um mecanismo inconsistente com a própria ideia de crescimento liderado pela demanda, e sem respaldo empírico adequado. Por consequência, a interpretação da referida equação deve ser diferente; ela deve ser vista apenas como uma condição de equilíbrio externo, e não também como uma equação de determinação da taxa de crescimento da demanda. Afinal, uma equação adequada para captar a taxa de crescimento da demanda deveria incorporar como caso geral as situações nas quais a política fiscal não gere equilíbrio orçamentário, e nas quais o investimento e a poupança interna não se equiparem por meio do mecanismo (equivocado) proposto. A proposta de Thirlwall de tratar a taxa efetiva de crescimento do PIB real no longo prazo $(g)$ como sendo determinada pela taxa mais baixa entre a taxa de crescimento real da demanda agregada $\left(g_{d}\right)$ e a taxa de crescimento máxima do PIB real doméstico compatível com a restrição externa $\left(g_{B P}\right)$ nos parece, nesse aspecto, bem mais adequada. Formalmente:

$$
g=\min \left\{g_{d}, g_{B P}\right\}
$$

Esta forma de colocar a questão permite desdobrar as possibilidades de crescimento regionais em dois cenários: a) crescimento restrito pela demanda $\left(g=g_{d}>g_{B P}\right)$; e $b$ ) crescimento restrito externamente $\left(g=g_{B P}<g d\right)$. Considerando que Kaldor colapsa (a nosso ver, equivocadamente) os dois cenários em apenas um, e que Thirlwall se detém mais no cenário " $b$ ", parece conveniente desdobrar em maiores detalhes os determinantes do crescimento no cenário “a”.

Mantida a teoria do acelerador/supermutiplicador como determinante do comportamento do investimento, a taxa de crescimento da demanda de longo prazo, implícita na equação do modelo de Kaldor, deveria ser substituída por ${ }^{3}$ :

$$
g_{d}=g_{d a}=c_{0} g_{c a}+g_{0} g_{g}+\left[1-c_{0}-g_{0}\right][(1+x) \hat{\theta}+x(1+\hat{\theta})]
$$

Em (2), $g_{d}$ é a taxa de crescimento da demanda agregada; $g_{d a}$ é a taxa de crescimento dos componentes autônomos da demanda agregada; $g_{c a}, g_{g}$ são respectiva-

\footnotetext{
3 Inspirada em Blecker (1998).
} 
mente as taxas de crescimento do consumo autônomo ${ }^{4}$ e do gasto governamental; $c_{0}$ e $g_{0}$ correspondem às participações, respectivamente, dos níveis de consumo autônomo e gasto governamental no nível de demanda autônoma agregada do período anterior; $x$ é a taxa de crescimento real das exportações; e $\hat{\theta}$ é a taxa de variação da taxa de câmbio real. Economicamente, a fórmula mostra que o crescimento da demanda agregada, sendo determinado pelo crescimento dos seus componentes autônomos, depende crucialmente do crescimento: a) do consumo autônomo; b) dos gastos governamentais; e c) das exportações; todos ponderados pelas respectivas participações na demanda agregada autônoma e, no caso de "c", também pelo comportamento da taxa de câmbio real.

Tanto Thirlwall quanto Kaldor adotam:

$$
\begin{aligned}
x & =\varepsilon g^{*}-\eta\left(\hat{e}+\pi^{*}-\pi\right) \\
m & =\xi g^{\star}-\Psi\left(\hat{e}+\pi^{\star}-\pi\right)
\end{aligned}
$$

Em (4), $g^{*}$ é a taxa de crescimento do PIB real "do resto do mundo"5; ê é a taxa de variação da taxa de câmbio nominal efetiva; $\pi^{*}$ é a taxa de inflação "do resto do mundo"; $\pi$ é a taxa de inflação doméstica; $\varepsilon, \xi>0$ são, respectivamente, as elasticidades-renda da demanda por exportações e importações; e $\eta, \psi<0$ são, respectivamente, a elasticidade-preço da demanda por exportações e importações. Em termos econômicos, a fórmula (3) expressa a dependência direta do crescimento das exportações reais de seus dois principais determinantes, quais sejam, a taxa de crescimento do PIB do resto do mundo e a taxa de variação da taxa de câmbio, ponderados pelas respectivas elasticidades; e a fórmula (4) expressa a dependência direta do crescimento das importações reais em relação à taxa de crescimento real do PIB doméstico, e a inversa em relação à taxa de variação da taxa de câmbio, ambas também ponderadas pelas respectivas elasticidades.

Como é sabido, o valor dessas elasticidades é fundamental para a delimitação das possibilidades de crescimento desses países nas abordagens de Kaldor e de Thirlwall. Este aspecto será retomado nos itens seguintes.

4 É importante ter em mente que dentro do consumo autônomo há uma parte referente à renda líquida enviada ao exterior, que serve de veículo de retroalimentação do saldo em transações correntes (restrição externa) para a taxa de crescimento da demanda agregada e a do produto efetivo.

5 O termo "resto do mundo" deve ser interpretado como correspondendo ao agregado ponderado dos principais parceiros comerciais (importação e/ou exportação, conforme o contexto), podendo se referir tanto a outros países quanto a outras regiões subnacionais. 
Empregando-se ainda a definição da taxa de variação da taxa de câmbio real $\hat{\theta}=\hat{\mathrm{e}}$ $+\pi^{\star}-\pi$ e supondo que os termos quadráticos possam ser desprezados para valores baixos, a substituição de (3) em (2) gera:

$$
\left.g_{d}=g_{d a}=c_{0} g_{c a}+g_{0} g_{g}+\left[1-c_{0}-g_{0}\right] \hat{[} \theta\left(1+2 \varepsilon g^{\star}-\eta\right)+\varepsilon g^{\star}\right]
$$

Assim, (5) permite explicitar o impacto dos determinantes do crescimento das exportações sobre a taxa de crescimento da demanda.

Para o correto desenvolvimento desta expressão não convém omitir o efeito direto da taxa de câmbio nominal sobre o processo de formação de preços em economias abertas. Para isso, ao invés da formulação kaldoriana tradicional, usaremos

$$
P=(Z W / A)^{1-f}\left(e P^{\star}\right)^{f}
$$

Em (6), $P$ é o nível geral de preços doméstico; $P^{\star}$ é o nível geral de preços do resto do mundo; "e" é o nível da taxa de câmbio nominal; $Z$ é $1+$ mark up médio (exógeno); $W$ é o salário nominal médio; $A$ é a produtividade média do trabalho; e $1>f>0$ corresponde ao peso do setor de bens comercializáveis na economia. Aplicando a (6) as taxas instantâneas de crescimento, chega-se $\mathrm{a}^{6}$ :

$$
\pi=(1-f)(z+w-a)+f\left(\hat{e}+\pi^{\star}\right)
$$

A partir da definição de $\hat{\theta}$ obtém-se:

$$
\hat{\theta}=(1-f)\left(\hat{e}+\pi^{*}-z-w+a\right)
$$

A lei de Verdoorn, ademais, conforme a formulação tradicional de Kaldor, acarreta:

$$
a=a_{a}+\lambda g
$$

Em (9), $a_{a}$ é a taxa de crescimento autônoma da produtividade média do trabalho; $g$ é a taxa de crescimento real do PIB doméstico; e $1>>\lambda>0$ é um parâmetro que estabelece a intensidade dos ganhos dinâmicos de escala enquanto geradores de crescimento da produtividade do trabalho.

\footnotetext{
${ }^{6}$ Evidentemente, no caso das economias subnacionais, $\hat{e}=0$ e $e=1$.
} 
Substituindo (8) e (9) em (5), obtém-se:

$\left.g_{d}=c_{0} g_{c a}+g_{0} g_{g}+\left\{1-c_{0}-g_{0}\right\}\left\{(1-f)\left(\hat{e}+\pi^{*}-z-w+a_{a}+\lambda g\right)\left(1+2 \varepsilon g^{*}-\eta\right)+\varepsilon g^{*}\right]\right\}$

Essa equação demonstra que, contrariamente ao que pretendiam as formalizações das ideias de Kaldor ${ }^{7}$, tanto os componentes autônomos domésticos da demanda autônoma quanto as exportações devem ser considerados como capazes de afetar a taxa de crescimento da demanda doméstica. $\mathrm{O}$ verdadeiro peso dessa conclusão, porém, depende do valor do parâmetro $c_{0}+g_{0}$, bem como do fato da economia encontrar-se ou não sob forte restrição externa. Em países/regiões relativamente abertos, o valor de tal parâmetro será relativamente baixo, e o papel das exportações seria mais enfatizado (sobre o papel do câmbio no crescimento, vide mais adiante). Contudo, essa não é uma conclusão em geral válida, pois em países/regiões de economias relativamente fechadas, o maior relevo será deslocado para os componentes domésticos da demanda. Ademais, se a economia se encontrar em situação de relativa folga em sua restrição externa, não haverá razão para que o crescimento tenha que ser necessariamente liderado pelas exportações.

Outro aspecto significativo a ser considerado na expressão acima é que, diferentemente do pretendido por Kaldor, ela não deve ser mais interpretada como válida em todas as circunstâncias, mas apenas quando não houver restrição externa, isto é, quando $g=g_{d}<g_{B P}$. Neste caso, fazendo $g=g_{d}$ em (10) chega-se a:

$$
g=\frac{c_{0} g_{c a}+g_{0} g_{g}+\left[1-c_{0}-g_{0}\right]\left[(1-f)\left(1+2 \varepsilon g^{\star}-\eta\right)\left(\hat{e}+\pi^{\star}-z-w+a_{a}\right)+\varepsilon g^{\star}\right]}{1-\left(1-c_{0}-g_{0}\right)(1-f)\left(1+2 \varepsilon g^{\star}-\eta\right) \lambda}
$$

Essa fórmula é a que determina o crescimento do PIB real doméstico no cenário de crescimento restringido pela demanda. Supõe-se que os parâmetros sejam tais que o denominador seja positivo.

A fórmula acima concretiza a possibilidade prevista por Blecker (2009) de que o crescimento dos componentes internos da demanda acelere o crescimento do produto e, este, via lei de Verdoorn, o da produtividade, gerando ganhos de competitividade que aceleram as exportações e novamente a demanda e o produto. Se estabeleceria assim um círculo virtuoso (ou vicioso, caso as variáveis se movessem em sentido inverso) cumulativo à la Myrdal (1957). A ideia fundamental a ser apreendida, por-

\footnotetext{
Mais uma vez, alertamos que tal observação se aplica às formalizações das ideias de Kaldor. Esse autor jamais supôs que as exportações fossem fundamentais para o crescimento da demanda em países grandes.
} 
tanto, é de que a existência de mecanismos de polarização entre países e/ou regiões mesmo em um contexto em que a restrição externa não estivesse ativa, ou seja, nos termos da equação (1), no cenário de restrição do crescimento pela demanda agregada, no qual $g=g_{d}<g_{B P}$.

\section{CRESCIMENTO NO ESPAÇO, RESTRIÇÃO EXTERNA E O FLUXO DE CAPITAIS - UMA RESENHA}

Voltemo-nos agora ao cenário no qual o crescimento encontra-se limitado pela restrição externa, ou seja, aquele em que $g=g_{B P}<g_{d}^{8}$. Tanto no modelo canônico de Thirlwall quanto no de Kaldor se optou por um conceito de restrição de balanço de pagamentos de longo prazo, no qual o equilíbrio externo é definido em termos do equilíbrio da balança comercial e de serviços (não fatores). Embora forneça um ponto de partida simples, esta escolha teórica envolve o que em certos momentos pode ser um requisito de equilíbrio externo excessivamente restritivo, considerando que não se pode negar aprioristicamente a possibilidade de expansão sustentável do passivo externo líquido (Medeiros e Serrano, 2001, p. 119). Ademais, em termos empíricos, como observa Silva Carvalho (1997, p. 89), a ausência desse fator pode ser responsável pelo fato de que a introdução de países subdesenvolvidos na amostra reduz a capacidade explicativa do modelo original de Thirlwall do processo de crescimento ${ }^{9}$. Tendo em vista esse aspecto, várias versões do modelo de Thirlwall, abandonando o tratamento da restrição externa do modelo original, tentaram incorporar a presença de fluxos de capitais na definição do equilíbrio externo.

A primeira tentativa nesse sentido parece ter sido a de Thirlwall e Hussain (1982), que modificava a restrição do balanço de pagamentos do modelo original simplesmente adicionando ao mesmo um fluxo de capitais exogenamente determinado. Tal solução, contudo, parece acarretar uma série de problemas. Em primeiro lugar, ela modifica a natureza da restrição externa considerada no modelo, pois passa a considerar como fator crucial para tal restrição a disponibilidade de reservas internacionais (resultantes da dinâmica conjunta da conta de capitais e financeira e do saldo em transações correntes) -, e não mais a evolução do passivo externo líquido, como no modelo original. Isso viola o caráter de longo prazo em que se costumam apoiar os modelos

\footnotetext{
8 Para uma discussão acerca das razões que levam a literatura heterodoxa a empregar o conceito de restrição externa mesmo no longo prazo, vide Lourenço et al. (2012).

9 O fato de os tratamentos empíricos do modelo de Thirlwall - diferentemente do modelo teórico - não distinguirem cuidadosamente o cenário de restrição do crescimento pela demanda do de restrição externa também pode ser um dos fatores explicativos desse fenômeno.
} 
de crescimento. O modelo resultante parece, assim, misturar indevidamente dois problemas qualitativamente distintos relacionados ao setor externo, quais sejam: a) o problema da sustentabilidade da trajetória do passivo externo líquido, tipicamente de longo prazo; b) o problema da disponibilidade de liquidez em moeda forte, de mais curto prazo $^{10}$.

Ademais, o tratamento do fluxo de capitais como exógeno - se era adequado ao contexto de seu uso pioneiro no modelo dos dois hiatos (Chenery e Bruno, 1962; Chenery e Strout, 1966), voltado a avaliar o impacto dos fluxos de ajuda externa sobre o crescimento - implica agora uma visão limitada da sua dinâmica. Pois, no contexto contemporâneo, é evidente que o financiamento dos deficits externos em transações correntes ocorre significativamente por capitais privados dotados de alta mobilidade. Desconsiderar os limites à manutenção continuada de tais fluxos acarreta, como observou Silva Carvalho (2007, p. 91), omitir: a) a limitação da oferta de financiamento pelos credores privados à expansão dos passivos externos líquidos; b) os custos decorrentes do aumento do passivo externo líquido percebidos pelos países/regiões que são devedores líquidos, que podem levá-los a decidir inclusive reduzir o seu crescimento no intuito de impedir a expansão desmesurada desses custos. Ainda segundo Silva Carvalho (2007), todos os fatores acima apontados devem ter alguma importância para explicar os resultados empíricos sofríveis dessa versão. Uma segunda tentativa de dar conta da introdução dos fluxos de capitais na modelagem da restrição externa aparece em McCombie (1997). Esse tratamento, porém, embora busque sanar várias das dificuldades presentes na tentativa anterior, como a introdução de restrições ao endividamento e da consideração dos seus custos, ainda padece de alguns problemas: a) segue o tratamento da restrição externa de Thirlwall e Hussain (1982); b) utiliza a paridade descoberta dos juros ${ }^{11}$ - uma relação sabidamente com pouco suporte empírico $^{12}$; c) a variável empregada para avaliação da sustentabilidade do passivo externo líquido é a razão entre este e o PIB doméstico, mas este último, medido em moeda nacional, não capta adequadamente o tamanho do descasamento de moedas (Eichengreen, Hausmann e Panizza, 2003) que dá origem ao problema de restrição externa; d) curiosamente, a única taxa de juros considerada no modelo como capaz de afetar a

\footnotetext{
${ }_{10}$ Para uma discussão desses conceitos, vide Medeiros e Serrano (2001, p. 119-125). Perceba que não está a se negar aqui a possibilidade de que um problema de insuficiência de reservas internacionais seja criado por uma trajetória insustentável do passivo externo líquido. Contudo, como os determinantes das trajetórias dessas duas variáveis são de natureza ao menos em parte distinta, justifica-se a nossa proposta de manutenção dessa separação.

${ }^{11}$ Conforme Silva Carvalho (2007, p. 91).

12 Em contrário, vide Olmo e Pilbean (2011).
} 
sustentabilidade da evolução do passivo externo líquido é a taxa de juros doméstica, e não a externa. Elliot e Rhodd (1999) propõem uma extensão a Thirlwall e Hussain (1982) que, posteriormente emendada por Ferreira (2001), pretende dar conta de eliminar algumas das restrições àquele modelo, em particular pela introdução dos serviços fatores na restrição de balanço de pagamentos. Contudo, o modelo em questão: a) não inclui os determinantes dos serviços fatores, o que impede uma apreciação adequada da condição de sustentabilidade da trajetória do passivo externo líquido; b) mantém o fluxo de capitais como essencialmente exógeno; c) na versão original de Elliot e Rhodd, o modelo mantém a concepção de equilíbrio de balanço de pagamentos de Thirlwall e Hussain, cujos problemas já expusemos anteriormente; d) na versão de Ferreira, volta-se à concepção de equilíbrio externo do modelo canônico de Thirlwall, a qual, como vimos, omite a possibilidade de expansão sustentável do passivo externo líquido.

Uma versão que recentemente chamou mais atenção, entre as que pretendem dotar os modelos heterodoxos de crescimento em economias abertas de um melhor aparelhamento modelístico, foi a de Moreno-Brid (2003), que buscava melhorar os resultados obtidos em Moreno-Brid (1998). Entre as novidades dessa versão incluem-se a separação dos serviços fatores dos não fatores, embora os determinantes dos primeiros continuem a ser omitidos; e a modelagem da restrição externa em duas partes, uma referida ao equilíbrio do balanço de pagamentos como um todo e outra referida apenas ao equilíbrio do saldo em transações correntes. A nosso ver, porém, embora essa versão de fato represente uma melhoria substancial em relação às versões anteriormente citadas, ela ainda traz em si elementos que obscurecem uma análise adequada da problemática da restrição externa. Além da já citada não endogeneização dos determinantes dos serviços fatores, convém citar: a) a ausência de modelagem dos determinantes do fluxo de capitais; b) no que concerne à taxa de crescimento máxima permitida pela restrição externa quando se considera o balanço de pagamentos como um todo, foi novamente utilizado, como em Thirlwall e Hussain (1982), um conceito de equilíbrio externo de curto prazo que não é coerente com o ambiente pressuposto pelos modelos de crescimento; c) no que diz respeito à taxa de crescimento máxima permitida pela restrição externa quando se considera apenas o impacto do saldo em transações correntes (de fato o mais condizente com o longo prazo), a imposição da restrição na forma de um teto à relação saldo em conta corrente/PIB doméstico mais uma vez incide no problema anteriormente apontado de não captar adequadamente o efeito do descasamento de moedas, posto que a dimensão do PIB doméstico não capta a capacidade de geração de divisas do país.

Um artigo de extração ligeiramente diferente, mas que possui elementos que podem ser analisados sob o prisma dos modelos heterodoxos de crescimento para eco- 
nomias abertas, é o de Barbosa-Filho (2001). Partindo de uma crítica a Moreno-Brid (1998), este propõe-se também a separar os serviços fatores dos não fatores, além de sanar o que ele considera ser uma fonte de instabilidade do modelo daquele autor ${ }^{13}$. Ademais, como o modelo é bem mais ambicioso, ele pretende ir além da mera definição adequada da restrição externa, mas conectar a discussão da determinação desta com as políticas monetária, fiscal e cambial.

Deixando de lado os demais aspectos concernentes ao trabalho de Barbosa-Filho, que transcendem o escopo do presente artigo, interessa-nos particularmente a forma como o autor desenha a restrição externa, e os resultados que obtém como condição de sustentabilidade do passivo externo líquido. Em primeiro lugar, convém observar que o autor supõe que o equilíbrio externo, mais uma vez como em Thirlwall e Hussain (1982), está remetido ao balanço de pagamentos como um todo, acarretando as complicações já referidas. Depois, pressupondo i) a não validade da condição de paridade de poder de compra; ii) a existência de uma curva de Phillips (novo-keynesiana) com um trade-off entre inflação e desemprego estável no curto prazo; iii) uma função IS estável; e iv) a validade da condição de paridade descoberta da taxa de juros ${ }^{14}$, o autor torna endógenas a taxa de variação da taxa de câmbio real (considerada como variável de equilíbrio do balanço de pagamentos) e a taxa de juros doméstica. Dadas essas hipóteses, a condição de sustentabilidade do passivo externo líquido é a mesma obtida por McCombie (1997), já tratada anteriormente: a de que a taxa de crescimento real do PIB doméstico permaneça acima do custo real da dívida em moeda local. Além das críticas que se colocam a tais concepções, é interessante elaborar aqui uma observação de Silva Carvalho (2007, p. 102): o tratamento que Barbosa-Filho dá às relações econômicas transforma a própria natureza do modelo. Ao invés de um modelo de crescimento heterodoxo, cujas relações causais expressam a operação do princípio da demanda efetiva e as limitações inerentes da estrutura produtiva do país/região ao crescimento, passamos a ter um modelo destinado a fomentar a discussão acerca do direcionamento da gestão macroeconômica de curto prazo, no qual as suposições adotadas subvertem, em maior ou menor medida, as causalidades supostas em Kaldor e Thirlwall.

Uma linha de pesquisa um pouco diferente acerca da discussão sobre restrição externa - mas a nosso ver perfeitamente compatível com a interpretação da mesma na linha Kaldor-Thirlwall-modelo dos 2 hiatos, e, portanto, capaz de servir como fonte de ricos aportes teóricos ${ }^{15}$ - parte da contribuição de Domar (1950). Tendo em vista o

\footnotetext{
${ }_{13}$ Sobre esse ponto, vide Silva Carvalho (2007, p. 99) para maiores detalhes.

${ }^{14}$ Incluindo, porém, um prêmio de risco exógeno.

15 Conforme a sugestão de Medeiros e Serrano (2001).
} 
(então previsto para breve) encerramento do Plano Marshall, esse autor estuda a possibilidade de criar um mecanismo permanente de financiamento do balanço de pagamentos do resto do mundo a partir de aportes fiscais persistentes dos EUA a um fundo rotativo, a serem estipulados como uma pequena fração do PIB daquele país. Pergunta-se então acerca das condições de estabilidade do mecanismo em questão, sob diferentes arranjos institucionais em termos de amortização das dívidas. Domar conclui que a condição necessária para a estabilidade do referido arranjo, compatível com o equilíbrio de longo prazo dos balanços de pagamentos, corresponde a uma situação na qual a taxa de crescimento do PIB real dos EUA é superior à sua taxa de juros de longo prazo.

Nota-se que a condição de estabilidade obtida por Domar não deve ser diretamente transposta para outros países, pois ela pressupõe: a) que o fluxo de capitais seja exogenamente determinado, pois se trata, no contexto do exercício do autor, de fluxos oficiais de recursos ${ }^{16}$; b) que o país em questão seja o emissor da moeda internacional (de modo que não haja o "descasamento de moedas"). Apenas nesses casos é razoável conduzir a discussão da estabilidade do endividamento externo contrapondo a taxa de expansão do PIB doméstico à taxa de juros também doméstica ${ }^{17}$.

Simonsen (1979) parece ter sido o primeiro a transpor a discussão de Domar para um contexto diverso, no qual o descasamento de moedas tornasse a questão da sustentabilidade do endividamento externo diferenciável da do endividamento público interno, tanto conceitual quanto formalmente. Ele concluiu que a manutenção da estabilidade da relação dívida externa líquida/exportações dependia crucialmente de a taxa de crescimento das exportações ser tendencialmente maior do que a taxa de juros externa média sobre ela incidente.

Convém observar algumas peculiaridades do resultado obtido. Ao estabelecer a restrição em termos da relação dívida externa líquida/exportações (e não PIB), o autor evita o erro de construir a análise em termos de variáveis que não captem a correta dimensão do descasamento de moedas. Por outro lado, a análise da sustentabilidade se restringe à dívida externa liquida (e não ao mais abrangente passivo externo líquido), o que exclui da análise o ônus gerado (na forma de remessas de lucros e dividendos) pelo capital de risco.

\footnotetext{
${ }^{16}$ Isso não pressupõe a inexistência de fluxos privados de capitais, mas sim que os fluxos oficiais seriam acionados, sempre que necessário, para complementar o volume daqueles. No contexto de baixa mobilidade de capitais então vigente, era plausível a expectativa de que os fluxos oficiais assumissem grande parte do ônus do ajuste.

${ }^{17}$ Como percebe o próprio Domar no mesmo artigo, nesse caso a condição de estabilidade da expansão do passivo externo líquido é bastante similar à de expansão do endividamento público interno.
} 
Outro aspecto notável do resultado de Simonsen consiste na curiosa assimetria entre o importante efeito do crescimento das exportações sobre a sustentabilidade da dívida e a completa ausência do crescimento das importações nesta. Rastreando as equações, é possível perceber que essa assimetria resulta da combinação entre: a) a escolha das exportações como denominador na razão-chave do modelo; b) a incorporação das importações na variável auxiliar hiato de recursos - definida como a diferença entre o deficit "primário" em transações correntes e o ingresso líquido de investimentos externos de risco -, bem como o fato de que, para obter a condição de sustentabilidade da relação dívida externa líquida/exportações, em determinado momento o autor é obrigado a impor a hipótese de que a relação hiato de recursos/exportações permaneça constante. Ao perfazer esse último passo, se está supondo (implicitamente) que a taxa de crescimento das importações permaneça tendencialmente igual à taxa de crescimento das exportações mais a taxa de crescimento da entrada líquida de capitais externos de risco. Conclui-se, portanto, que a validade estrita da célebre "condição de sustentabilidade da dívida externa" ( $\left.x \geq i^{\star}\right)$ está condicionada a essa última igualdade, de modo que se a taxa de crescimento das importações for superior à taxa-limite supradefinida, a condição em questão não será suficiente para manter a relação dívida líquida externa/exportações estável (e vice-versa). Em suma, a condição em questão nem sempre será suficiente para garantir a estabilidade do endividamento externo; de modo que ela não é a verdadeira condição de estabilidade, mas apenas uma forma matemática reduzida, cômoda pela simplicidade, mas equivocada se interpretada estritamente.

Dadas as limitações que foram apresentadas sucessivamente pelos diversos modelos que se dispuseram a delimitar as condições de sustentabilidade do processo de acumulação de passivos externos líquidos, parece haver espaço para uma contribuição que procure elucidar esses aspectos. É o que passaremos a fazer no item seguinte, baseados nos autores supracitados.

\section{CRESCIMENTO NO ESPAÇO, RESTRIÇÃO EXTERNA E O FLUXO DE CAPITAIS - UMA PROPOSTA}

Sejam as definições contábeis arquiconhecidas:

$$
P E L_{t}=P E L_{t-1}-S T C_{t}
$$

Em (12), PEL é o passivo externo líquido e STC é o saldo em transações correntes; e

$$
S T C_{t}=X_{t}-M_{t}-R L E_{t}
$$


Em (13), $X$ e $M$ correspondem, respectivamente, aos níveis de exportações e importações de bens e serviços não fatores, e $R L E$ consiste na renda líquida enviada ao exterior. É razoável admitir que: ${ }^{18}$

$$
R L E_{t}=r^{\star} P E L_{t-1}
$$

Em (14), r* é o custo (em termos percentuais) da manutenção pelos residentes dos passivos externos líquidos ${ }^{19}$. Substituindo-se (13) e (14) em (12) obtém-se:

$$
P E L_{t}=P E L_{t-1}-X_{t}+M_{t}+r^{*} P E L_{t-1}
$$

ou

$$
P E L_{t}=\left(1+r^{*}\right) P E L_{t-1}-X_{t}+M_{t}
$$

Aplicando-se a essa expressão as definições de taxa de crescimento das exportações e das importações:

$$
\begin{gathered}
X_{t}=X_{t-1}(1+x) \\
M_{t}=M_{t-1}(1+m)
\end{gathered}
$$

Em (16), $x$ é a taxa de crescimento das exportações e $m$ a taxa de crescimento das importações. Segue-se que:

$$
P E L_{t}=\left(1+r^{*}\right) P E L_{t-1}-X_{t-1}(1+x)+M_{t-1}(1+m)
$$

Dividindo ambos os lados por $P E L_{t-1}$, tem-se:

$$
P E L_{t} / P E L_{t-1}=\left(1+r^{*}\right)-X_{t-1} / P E L_{t-1}(1+x)+M_{t-1} / P E L_{t-1}(1+m)
$$

Sejam definidas as variáveis auxiliares $\alpha$ e $\beta$ de tal forma que:

\footnotetext{
${ }^{18}$ Poderia ser facilmente adaptado um termo adicional autônomo à renda líquida enviada ao exterior, especialmente no caso da análise de países nos quais fosse interessante captar os efeitos da ajuda externa, das remessas de emigrantes etc.

19 Inclusive prêmio de risco.
} 


$$
\begin{aligned}
& \alpha=M_{t-1} / P E L_{t-1} \\
& \beta=X_{t-1} / P E L_{t-1}
\end{aligned}
$$

Então, aplicando-as à equação (18), obtemos:

$$
P E L_{t} / P E L_{t-1}=1+r^{*}-\beta(1+x)+\alpha(1+m)
$$

ou

$$
\left(P E L_{t} / P E L_{t-1}\right)-1=r^{*}-\beta(1+x)+\alpha(1+m)
$$

Substituindo-se as equações (3) e (4) na expressão (19), obtemos:

$$
\left(P E L_{t} / P E L_{t-1}\right)-1=r^{*}-\beta\left[1+\varepsilon g^{*}-\eta\left(\hat{e}+\pi^{*}-\pi\right)\right]+\alpha\left[1+\xi g+\Psi\left(\hat{e}+\pi^{*}-\pi\right)\right]
$$

Desenvolvendo, obtemos sucessivamente:

$$
\left(P E L_{t} / P E L_{t-1}\right)-1=r^{*}-\beta\left(1+\varepsilon g^{*}\right)+\beta \eta\left(\hat{e}+\pi^{*}-\pi\right)+\alpha(1+\xi g)+\alpha \Psi\left(\hat{e}+\pi^{*}-\pi\right)
$$

e

$$
\left(P E L_{t} / P E L_{t-1}\right)-1=r^{*}-\beta\left(1+\varepsilon g^{*}\right)+(\beta \eta+\alpha \Psi)\left(\hat{e}+\pi^{*}-\pi\right)+\alpha+\alpha \xi g
$$

Resolvendo para g, temos:

$$
g=\frac{\left(P E L_{t} / P E L_{t-1}\right)-1-r^{\star}+\beta\left(1+\varepsilon g^{\star}\right)-(\beta \eta+\alpha \psi)\left(\hat{e}+\pi^{\star}-\pi\right)-\alpha}{\alpha \xi}
$$

Seja $g_{B P}$ a taxa máxima de crescimento de longo prazo permitida pela situação do balanço de pagamentos, consideraremos que o crescimento do passivo externo líquido é sustentável quando sua participação na riqueza mundial permanece estável. Supondo que a riqueza mundial cresça a uma taxa $g^{\star}$, temos que:

$$
g=g_{B P} \text { quando }\left(P E L_{t} / P E L_{t}-1\right)-1=g^{*}
$$

Aplicando essa expressão a (24) obtemos:

$$
g_{B P}=\frac{g^{*}-r^{*}+\beta\left(1+\varepsilon g^{\star}\right)-(\beta \eta+\alpha \Psi)\left(\hat{e}+\pi^{*}-\pi\right)-\alpha}{\alpha \xi}
$$


ou, desenvolvendo-a,

$$
\begin{gathered}
g_{B P}=\frac{g^{\star}-r^{\star}+\beta+\beta \varepsilon g^{*}-(\beta \eta+\alpha \Psi)\left(\hat{e}+\pi^{\star}-\pi\right)-\alpha}{\alpha \xi} \\
g_{B P}=\frac{g^{\star}(1+\beta \varepsilon)-r^{\star}-(\beta \eta+\alpha \Psi)\left(\hat{e}+\pi^{\star}-\pi\right)-\alpha}{\alpha \xi}
\end{gathered}
$$

A expressão (26) finalmente representa a taxa de crescimento máxima permitida pela situação do balanço de pagamentos, ou seja, expressa aquela que, a nosso ver, é a melhor forma de introduzir a restrição externa ${ }^{20}$.

Segundo essa expressão, a restrição externa será tão mais forte (menor $g_{B P}$ ) quanto:

- menor for a taxa real de crescimento do PIB do resto do mundo $g^{\star}$;

- maior for o custo relativo $r^{*}$ do passivo externo líquido;

- menor $^{21}$ for a taxa de variação da taxa real de câmbio ( $\left.\hat{\mathrm{e}}+\pi^{\star}-\pi\right)$;

- menor for a elasticidade-renda da demanda por exportações $(\varepsilon)$, e

- Maior for a das importações $(\xi)^{22}$.

Também é interessante observar que, caso a hipótese de paridade de poder de compra (PPC) seja válida ${ }^{23}\left(\hat{e}+\pi^{\star}-\pi=0\right)$, a equação acima ficará reduzida $\mathrm{a}^{24}$ :

$$
g_{B P}=\frac{g^{\star}(1+\beta \varepsilon)-r^{*}+\beta-\alpha}{\alpha \xi}
$$

Parece interessante tecer alguns comentários acerca das peculiaridades que cercam a solução encontrada na equação (27). Primeiramente, é interessante observar que ao considerarmos que o crescimento do passivo externo líquido é sustentável quando sua participação na riqueza mundial permanece estável, estamos afirmando que a taxa máxima de expansão do passivo externo líquido aceitável pelos credores líquidos do país/ região é igual à taxa de crescimento do PIB do resto do mundo, o que impede que a participação deste no portfólio dos agentes do resto do mundo cresça explosivamente.

${ }^{20}$ Repare que a fórmula em questão é aplicável tanto aos casos de PEL positivo quanto negativo. Embora nesse último caso a restrição provavelmente não se aplique e o país passe a ter seu crescimento limitado pela demanda, ainda assim a fórmula mostra adequadamente o ponto de transição entre os dois regimes.

${ }^{21}$ Se a condição de Marshall-Lerner for válida; caso contrário o efeito se inverte.

${ }^{22}$ Os efeitos de $\alpha, \beta$, $\eta$ e $\psi$ sobre $g_{B P}$ são dúbios, e dependem crucialmente do sinal de $\hat{e}+\pi^{\star}-\pi$.

${ }^{23}$ Sobre as circunstâncias em que a PPC se torna válida, bem como seus efeitos nesse tipo de modelo, vide Lourenço et al. (2012), bem como Ferrari, Freitas e Barbosa Filho. (2010).

${ }^{24}$ Nesse caso é possível concluir que um aumento em $\beta$ muito provavelmente geraria uma melhoria da restrição externa, pois $\frac{\partial g_{B P}}{\partial \beta}=1+\varepsilon g^{*}$; já no que diz respeito a $\alpha$, o efeito é provavelmente negativo, ao menos em situações em que $g^{*}>r^{*}$, pois $\frac{\partial g_{B P}}{\partial \alpha}=\frac{r^{*}-g^{*}(1+\beta \varepsilon)-\beta}{\xi \alpha^{2}}$. 
Essa forma de modelar a restrição externa possui algumas propriedades interessantes, quais sejam: i) ela não depende de uma razão entre variáveis que denotam passivos e capacidade de pagamento em unidades monetárias diferentes; o uso de uma relação em que tanto o numerador quanto o denominador são mensurados na mesma moeda permite avaliar adequadamente o efeito do descasamento de moedas; ii) ela não impõe o equilíbrio forçado conjunto da conta de capitais e da conta corrente, portanto, não desloca o foco de análise para o curto prazo; iii) ela tampouco impõe o equilíbrio forçado do saldo em transações correntes, não impondo aprioristicamente o desaparecimento dos deficits/superavits e sim permitindo a sua continuidade, sem, porém, permitir seu crescimento explosivo; iv) ela não oculta hipóteses implícitas em variáveis auxiliares ( $\alpha$ e $\beta$ ), que aliás mudam a cada período; v) o fluxo de capitais é tratado endogenamente, dependendo crucialmente da evolução da riqueza e renda mundiais; vi) os determinantes dos serviços não fatores são devidamente individualizados; vii) o crescimento das importações e das exportações geram efeitos simétricos sobre a restrição externa; viii) tanto a limitação da oferta de financiamento pelos credores privados à expansão dos passivos externos líquidos quanto os custos decorrentes do aumento do passivo externo líquido nos países que são devedores líquidos ficam claramente modelados; ix) preserva em sua essência as relações causais à la KaldorThirlwall, evitando misturar ao modelo aspectos que não dizem respeito ao cenário típico dos modelos de crescimento; $\mathrm{x}$ ) a restrição externa é estabelecida em termos dos determinantes do crescimento do passivo externo líquido, conceito mais amplo, e não da dívida externa líquida, mais restrita.

É evidente que o ônus relativo do passivo externo líquido $\left(r^{\star}\right)$ depende da taxa de juros externa. Mas nada impede que ele dependa também da taxa de juros interna se e na medida em que os não residentes estejam dispostos a adquirir ativos emitidos em moeda doméstica. Evidentemente, isso é muito diferente de afirmar, como fazem alguns modelos, que a taxa de referência para determinação da sustentabilidade da dívida externa é exclusivamente a taxa de juros doméstica. Contudo, a diferença mais perceptível da modelagem acima em relação aos modelos de Kaldor e de Thirlwall (para além da possibilidade de endividamento externo sustentável) parece ser a de que o crescimento mundial exerce um efeito positivo sobre $g_{B P}$ não apenas pela via das exportações, mas também pelo aumento da capacidade de absorção dos portfólios do resto do mundo em relação aos passivos externos líquidos dos países.

Para efeito de avaliação, pode ser interessante comparar a fórmula (27) com a versão mais simples da "lei de Thirlwall":

$$
g_{B P}=\frac{\varepsilon g^{*}}{\xi}
$$


O efeito de expansão dos portfólios mundiais claramente agrega, na fórmula (27) anteriormente explicitada, elementos adicionais de multiplicação à taxa de crescimento do PIB do resto do mundo, enquanto nos modelos canônicos de Kaldor e de Thirlwall essa taxa é multiplicada apenas pela elasticidade-renda da demanda por exportações. Não resulta daí, contudo, que a possibilidade de deficits em conta corrente necessariamente alargue as possibilidades de crescimento, nem que os processos de polarização sejam necessariamente reduzidos.

Para um aprofundamento desse ponto, convém comparar as taxas máximas de crescimento permitidas pela restrição externa $\left(g_{B P}\right)$ nos dois modelos. Assim, se a possibilidade de deficits sustentados em conta corrente relaxar de fato a restrição externa, teremos:

$$
g_{B P} \text { (eq. 24) }>g_{B P} \text { (Thirlwall, eq. 28) } \rightarrow \frac{g^{\star}(1+\beta \varepsilon)-r^{*}+\beta-\alpha}{\alpha \xi}>\frac{\varepsilon g^{\star}}{\xi}
$$

ou, desenvolvendo a inequação acima algebricamente:

$$
g^{*}+(\beta-\alpha)\left(1+\varepsilon g^{*}\right)>r^{*}
$$

Caso contrário, a possibilidade de acesso a fluxo de capitais externos que permitam deficits sustentados inevitavelmente implicará em aperto da restrição externa e menor potencial de crescimento.

Finalmente, em Thirlwall o potencial de polarização presente no modelo é facilmente perceptível quando se considera que, no caso dos países/regiões pobres, a mais provável configuração das elasticidades-renda das demandas por exportações e importações $(\varepsilon<1, \xi>1)$ implica:

$$
\left.\frac{\partial g_{B P}}{\partial g^{\star}}\right|_{\text {Thirlwall, regiões pobres }}=\frac{\varepsilon}{\xi}<1
$$

Isso acarreta o crescimento mais lento para esta que a média do resto do mundo (enquanto o oposto ocorre no caso dos países/regiões ricos).

Avaliação similar do potencial de polarização na presente modelagem revela um cenário mais complexo, na medida em que procedimento similar gera:

$$
\left.\frac{\partial g_{B P}}{\partial g^{*}}\right|_{\text {presente modelo }}=\frac{1+\beta \varepsilon}{\alpha \xi}
$$


A possibilidade de predomínio das forças de polarização será tão maior quanto, coeteris paribus:

- maiores forem as elasticidades-renda da demanda por importações $(\xi)$ dos países/regiões pobres, e menores as dos ricos;

- menores forem as elasticidades-renda da demanda por exportações $(\varepsilon)$ dos países/regiões pobres, e maiores as dos ricos;

- maiores forem as relações importações/PEL $(\alpha)$ dos países/regiões pobres, e menores forem as dos ricos;

- menores forem as relações exportações/PEL ( $\beta$ ) dos países/regiões pobres, e maiores as dos ricos.

\section{CONCLUSÃO}

O presente texto pretendeu colaborar no processo de construção de um paradigma macroteórico e heterodoxo de análise do processo de crescimento em economias abertas. O ponto de partida consistiu na releitura crítica dos modelos de Kaldor e de Thirlwall em suas versões canônicas, visando estabelecer os aspectos comuns a ambos e que servem de coluna vertebral à construção do edifício teórico almejado. Contudo, foram apontados aspectos de ambos os modelos que acarretam uma construção teórica inadequada e, portanto, uma percepção equivocada acerca da operação da restrição externa e do próprio processo de crescimento, em particular a ausência de modelagem do crescimento da demanda agregada e do fluxo de capitais externos. Estes acarretam ora a subestimação, ora a superestimação da taxa máxima de crescimento atingível, e uma interpretação por vezes equivocada da relação entre crescimento econômico e restrição externa.

Para dar conta da conexão adequada entre crescimento liderado pela demanda agregada e crescimento restringido pelo balanço de pagamentos, foram construídos dois possíveis cenários de crescimento. $\mathrm{O}$ primeiro cenário, trabalhado no segundo item do artigo, supôs que a taxa de crescimento do PIB real vigente é inferior à taxa máxima de crescimento permitida pela situação do balanço de pagamentos. Nesse caso, pode-se afirmar estritamente que o crescimento da economia se encontra limitado pelo crescimento insuficiente da demanda agregada. Uma vez que adotemos, em linha com Kaldor-Thirlwall, a hipótese de que o investimento é regido em longo prazo pela lógica do acelerador/supermultiplicador, a taxa de crescimento da demanda agregada passa a ser determinada pela taxa média ponderada de crescimento dos três componentes de demanda autônoma, quais sejam: o consumo autônomo, o gasto governamental e as exportações. Tomando as duas primeiras como exógenas, tratou-se de 
modelar a terceira, admitindo-se, à la Kaldor, a possibilidade de violação da hipótese de paridade de poder de compra mesmo no longo prazo. O resultado, consubstanciado na equação (11), implica que políticas de expansão da demanda doméstica tendem a elevar o crescimento do PIB tanto direta quanto indiretamente, pelo seu efeito sobre o crescimento das exportações. Esse último provém do ganho dinâmico de escala fornecido pelo crescimento do mercado doméstico. Surge então a possibilidade de que se estabeleçam círculos viciosos/virtuosos cumulativos à la Myrdal - e, portanto, prevalência dos efeitos de polarização do crescimento - mesmo quando a economia não se encontra em uma situação de crescimento restringido pelo balanço de pagamentos.

No que concerne à possibilidade de uso da política cambial nesse cenário, o modelo desenvolvido ocupa um meio termo entre os modelos canônicos de Kaldor (no qual ela sempre é eficaz, ao menos em termos de variações do câmbio) e de Thirlwall (no qual a imposição da hipótese de paridade de poder de compra elimina de saída qualquer margem de eficácia). A não imposição a priori dessa última hipótese deixa aberta alguma margem de manobra para a política cambial como instrumento indutor ao crescimento das exportações, da demanda agregada e do PIB real. Contudo, a consideração do impacto inflacionário direto de desvalorizações cambiais nominais (ausente em Kaldor) opera no sentido de reduzir o escopo de variação da taxa de variação do câmbio real e, portanto, a eficácia da política cambial. Atente-se para o fato de que a eventual consideração em trabalhos futuros da indexação salarial, ainda que parcial, reduziria ainda mais tal eficácia.

O segundo cenário supõe que a tentativa de aceleração do crescimento pela via da expansão da demanda agregada doméstica foi levada longe demais, e como consequência a economia passa por uma mudança de regime, operando então sob restrição externa. Nesse contexto, a equação relevante para a determinação da taxa de crescimento do PIB real passa a ser (26) ao invés de (11). O desenvolvimento dessa equação é encetado no quarto item do artigo, e foi beneficiado pela resenha, no terceiro item, das várias versões propostas pela literatura como extensões dos modelos de Kaldor e de Thirlwall. Nesse contexto se deu a maior inovação do presente artigo, qual seja, modelar uma restrição externa de longo prazo de forma a manter a possibilidade de geração de deficits/superavits permanentes em conta corrente, sem que eles, contudo, acarretem o crescimento explosivo do passivo externo líquido. Seu cerne se lastreou na construção alternativa da restrição ao crescimento do passivo externo líquido, baseada no princípio de que o crescimento do passivo externo líquido é sustentável enquanto sua participação na riqueza mundial permanecer estável.

Na nova fórmula, além do custo do passivo externo líquido aparecer como determinante da taxa limite de crescimento, o crescimento do PIB mundial passa a influenciá-la por outro canal além do tradicional das exportações: o maior crescimento mun- 
dial implica maior capacidade de absorção para os passivos emitidos pelos residentes no portfólio dos não residentes. Ambos os elementos apontam para o aumento do peso dos fatores externos, fora do controle da política econômica nacional, na formulação da restrição externa ao crescimento.

No campo empírico, os resultados (Lima e Silva, 2013) parecem apontar para o bom desempenho do modelo em relação às alternativas. Cabe ressaltar que o tratamento empírico da contribuição original de Thirlwall, presente em muitos trabalhos, supõe implicitamente que a economia esteja o tempo todo operando no cenário de restrição externa, o que, como vimos, não parece uma descrição adequada da operação de uma economia capitalista.

Outra inovação que o artigo pretendeu encaminhar foi responder se, e em que medida, o fato de uma economia poder operar de forma sustentada com deficits permanentes em transações correntes implica uma restrição externa mais frouxa e, portanto, possibilidade de crescimento econômico permanentemente mais elevado. A equação (24) estabeleceu formalmente a condição necessária para que isso ocorra, mostrando que a possibilidade de maior relaxamento ou arrocho da restrição externa depende crucialmente da relação entre o crescimento do PIB mundial $\left(g^{\star}\right)$ e o custo dos passivos externos líquidos $\left(r^{*}\right)$. Caso $g^{\star}$ seja suficientemente alta em relação a $r^{\star}$, a taxa de crescimento máxima permitida pela restrição externa será mais elevada do que a obtida a partir dos modelos canônicos, e vice-versa.

Finalmente, procurou-se responder se, e em que medida, o processo de polarização gerado no cenário de crescimento sob restrição externa é mais forte ou mais fraco do que o previsto no modelo canônico de Thirlwall. Concluiu-se, a partir da inequação (25), que não há resposta inequívoca a essa questão. Ela depende crucialmente do histórico de fragilidade externa da economia, sintetizada nas relações pretéritas exportações/passivo externo líquido $(\beta)$ e importações/passivo externo líquido $(\alpha)$ dos países relativamente ricos e pobres. Foi possível, porém, generalizar a seguinte relação: quanto mais altos os parâmetros alfa dos países pobres, e quanto mais baixos seus parâmetros beta - em suma, quanto maior a fragilidade externa por eles herdada do passado - maior a tendência de polarização vis-à-vis o previsto pelo Thirlwall original. O oposto ocorre em relação aos mesmos parâmetros dos países ricos.

Assim, a modelagem desenvolvida no presente artigo permitiu matizar uma série de respostas oferecidas pelas contribuições pioneiras de Kaldor e Thirlwall a questões fundamentais acerca da relação entre crescimento econômico e restrição externa. Em geral, tais qualificações envolveram dois aspectos centrais: a necessidade de se operar com dois cenários diversos, conforme o fator de restrição ao crescimento seja a demanda efetiva ou o balanço de pagamentos; e a necessidade de se considerar devidamente os aspectos financeiros da restrição externa. Esse último aspecto, materializado nos parâmetros alfa, 
beta e $r *$ do modelo, foi crucial para: a) estabelecer adequadamente a taxa máxima de crescimento permitida pela restrição externa; b) informar se, e em que medida, a possibilidade de operar com deficits permanentes (mas não explosivos) em transações correntes permite ou não acelerar o crescimento econômico; e c) dimensionar adequadamente o vigor dos mecanismos de polarização vigentes na economia mundial, fator crucial para compreensão da crescente concentração mundial da renda e da riqueza.

\section{REFERÊNCIAS BIBLIOGRÁFICAS}

AMADEO, E.; DUTT, A. K. Keynes's third alternative. Londres: Edward Elgar, 1990.

BARBOSA-FILHO, N. H. The balance-of-payments constraint: from balanced trade to sustainable debt. BNL Quarterly Review, n. 219, dez. 2001.

BHADURI, A.; MARGLIN, S. Unemployment and the real wage: the economic basis for contesting political ideologies. Cambridge Journal of Economics, v. 14, p. 375-393, 1990.

BLECKER, R. A. Long-run growth in open economies: export-led cumulative causation or a balance-of-payments constraint? In: KEYNESIAN MACROECONOMICS AND EUROPEAN ECONOMIC POLICIES, RESEARCH NETWORK MACROECONOMICS AND POLICIES, Berlim, 2-9 ago. 2009.

BLECKER, R. A. International competitiveness, relative wages, and the balance-of-payments constraint. Journal of Post Keynesian Economics, v. 20, n. 4, 1998.

CANO, W. Desequilíbrios regionais e concentração industrial no Brasil: 1930-1995. 2. ed. rev. aum. Campinas, SP: Unicamp, 1998.

CARVALHO, F. J. C. Alternative analysis of short and long run in post Keynesian economics. The Journal of Post Keynesian Economics, n. 2, v. 7, 1985.

CHENERY, HBRUNO, M. Development alternatives in an open economy: the case of Israel. Economic Journal, mar. 1962.

CHENERY, H.; STROUT, A. Foreign assistance and economic development. American Economic Review, v. 61, set. 1966.

CORNWALL, J. Modern capitalism: its growth and transformation. Londres: Martin Robertson, 1977.

DAVIDSON, P. International money and the real world. Londres: Macmillan Press, 1982.

DAVIDSON, P. Post Keynesian macroeconomic theory. Aldershot: Edward Elgar, 1994.

DOMAR, E. The effect of foreign investment on the balance of payments. American Economic Review, 1950.

DOSI, G., FAGIOLO, G.; ROVENTINI, A. An evolutionary model of endogenous business cycles. In: WILD@ACE 2004 CONFERENCE, Moncalieri, Itália, 3-4 dez. 2004.

DOW, S. C. The capital account and regional balance of payments problems. Urban Studies, jun. 1986. 
EICHENGREEN, B.; HAUSMANN, R.; PANIZZA, U. Currency mismatches, debt intolerance, and original sin: why they are not the same and why it matters. NBER Working Paper, n. 10036, out. 2003.

EICHNER, A. S. A theory of the determination of the mark-up under oligopoly. The Economic Journal, v. 83, n. 332, p. 1184-1200, dez. 1973.

ELLIOT, D.R.; RHODD, R. Explaining growth rate differences in highly indebted countries: an extension to Thirlwall and Hussain. Applied Economics, v. 31, set. 1999.

FERRARI, M. A. R.; FREITAS, F. N. P.; BARBOSA FILHO, N. H. O papel da taxa de câmbio real nos modelos de restrição externa: uma proposta de releitura com elasticidades endógenas. In: ENCONTRO DA ASSOCIAÇÃO KEYNESIANA BRASILEIRA (AKB), 2, São Paulo, 2010.

FERREIRA, A. A lei de crescimento de Thirlwall. Dissertação (Mestrado em Economia). Instituto de Economia, Universidade Estadual de Campinas, Campinas, SP, 2011.

FREITAS, F. Estabilidade e pleno emprego: as origens do esquema de Kaldor para a análise da flutuação e do crescimento econômico. Revista de Economia Política, v. 29, n. 1, São Paulo, jan./mar. 2009.

FREITAS, F. Uma análise crítica do modelo kaldoriano de crescimento liderado pelas exportações. In: ENCONTRO NACIONAL DE ECONOMIA, 31, Porto Seguro/BA, 2003.

GAREGNANI, P. On a change in the notion of equilibrium in recent work on value and distribution, 1976.

GTDN (1960). Uma política de desenvolvimento econômico para o Nordeste. Revista Econômica do Nordeste, v. 28, n. 4, p. 387-432, out./dez., 1997.

HUME, D. (1777). Writings on Economics. Madison: The University of Wisconsin Press. São Paulo: Abril Cultural, 1983[1777].

KALDOR, N. The case for regional policies. Scottish Journal of Political Economy, p. 338-348, nov. 1970.

KALECKI, M. Theory of economic dynamic. 2. ed. Londres: Allen and Unwin, 1965.

KEYNES, J. M. The general theory of interest, employment and money. Londres: Macmillan, 1936.

KINDLEBERGER, C. P. Europes's postwar growth. The role of the labour supply. Cambridge, MA: Harvard University Press, 1967.

LAVOIE, M. Foundations of post Keynesian economic analysis. Aldershot: Edward Elgar, 1992.

LEWIS, W. A. Economic development with unlimited supplies of labour. The Manchester School, mai. 1954.

LIMA E SILVA, A. Crescimento econômico e restrição externa: evidências empíricas para a economia brasileira (1991-2010). Dissertação (Mestrado em Economia). Departamento de Economia, Universidade Federal do Rio Grande do Norte, Natal, RN, 2013.

LOURENÇO, A. L. C.; BEZERRA, M. M. O.; SILVA, M. G.; PEREIRA, W. E. N. De volta a Furtado via Kaldor e Thirlwall: as teorias heterodoxas do crescimento como suporte para a retomada do enfoque furtadiano da questão regional. Revista Econômica do Nordeste, v. 43,p. 339-355, 2012. 
MARX, K. O Capital: crítica da economia política. Rio de Janeiro: Editora Bertrand Brasil, 1988.

MCCOMBIE, J. S. L. "Economic growth and the balance-of-payments constraint revisited". In: ARESTIS, P.; PALMA, G.; SAWYER, M. (Eds.) Markets, unemployment and economic policy, v. 2. Londres: Routledge, 1997.

MCCOMBIE, J. S. L.; THIRLWALL, A. P. Economic growth and the balance-of-payments constraint. Londres: Macmillan, 1994.

MEDEIROS, C. A. SERRANO, F. “Inserção externa, exportações e crescimento no Brasil”. In: FIORI, J. L. (Org.) Polarização mundial e crescimento. Petrópolis: Vozes, 2001.

MINSKY, H. P. Stabilizing an unstable economy. New Haven: Yale University Press, 1986.

MORENO-BRID, J. C. On capital flows and the balance-of-payments constrained growth model. Journal of Post Keynesian Economics, v. 21, n. 2, Winter, 1998.

MORENO-BRID, J. C. Capital flows, interest payments and the balance-of-payments-constrained growth model: a theoretical and empirical analysis. Metroeconomica, v. 54, n. 2, 2003.

MYRDAL, G. Economic theory and underdeveloped regions. London: Duckworth, 1957.

OLMO, J.; PILBEAN, K. Uncovered interest parity and the efficiency of the foreign exchange market: a re-examination of the evidence. International Journal of Finance and Economics, v. 16, n. 2 , abr. 2011

ROBINSON, J. Further contributions to modern economics. Oxford: Basil Blackwell. São Paulo: Vértice, Editora Revista dos Tribunais, 1988.

PORCILE, G.; LIMA, G.T. Real exchange rate and elasticity of labor supply in a balance of payments constrained macrodynamics. Cambridge Journal of Economics, dez. 2009.

SHACKLE, G. L. S. Uncertainty in economics and other reflections. Cambridge: Cambridge University Press, 1968.

SERRANO, F. Long period effective demand and the Sraffian Supermultiplier. Contributions to Political Economy, v. 14, p. 67-90, 1995.

SETTERFIELD, M.; CORNWALL, J. "A neo-Kaldorian perspective on the rise and decline of the Golden Age”. In: SETTERFIELD, M. (Ed.) The economics of demand-led growth: challenging the supply-side vision of the long run. Cheltenham: Edward Elgar, 2002.

SILVA CARVALHO, V. R. A restrição externa e a perda de dinamismo da economia brasileira: investigando as relações entre estrutura produtiva e crescimento econômico. Prêmio BNDES de Economia, 29, Categoria Dissertação de Mestrado. Rio de Janeiro: BNDES, 2007.

SIMONSEN, M. H. Pagamenti internazionale e indebitamento esterno. Rivista di Politica Economica, jan. 1979.

THIRLWALL, A. P. The balance-of-payments constraint as an explanation of international growth rate differences. Banca Nazionale del Lavoro Quarterly Review, p. 45-55, mar. 1979.

THIRLWALL, A. P. The nature of economic growth: an alternative framework for understanding the performance of nations. Cheltenhan: Edward Elgar. Brasília: Ipea, 2005.

THIRLWALL, A. P.; DIXON, R. J. "A model of export-led growth with a balance of payments constraint”. In: BOWERS, J. K. (Ed.) Inflation, development and integration. Leeds: Leeds University Press, 1979. 
THIRLWALL, A. P.; HUSSAIN, N. M. The balance of payments constraint, capital flows and growth rate differences between developing countries. Oxford Economic Papers, nov. 1982.

VERDOORN, P. J. Fattori che Regolano lo Sviluppo della Produttivita del Lavoro. L'Industria. London: Macmillan, 1949.

YOUNG, A. Increasing returns and economic progress. The Economic Journal, dez. 1928.

ZINI Jr., A. A. Taxa de câmbio e política cambial no Brasil. São Paulo: Edusp, 1995. 